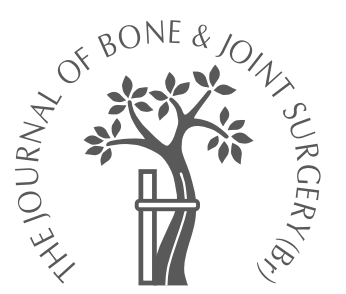

P. E. Beaulé, M. Krismer, P. Mayrhofer, S. Wanner, M. Le Duff, M. Mattesich, B. Stoeckl, H. C. Amstutz, R. Biedermann

From the Orthopaedic Hospital, Los Angeles, USA

P. E. Beaulé, MD, FRCSE, Assistant Clinical Professo M. Le Duff, MA, Clinical Research Coordinator H. C. Amstutz, MD, Medical Director

Joint Replacement Institute at the Orthopaedic Hospital, Los Angeles, California 90007, USA.

M. Krismer, MD, Professor - S. Wanner, MD, Registrar M. Mattesich, MD, Registrar B. Stoeckl, MD, Senior Consultant

n. Biedermann, MD, Senior Consultant

Department of Orthopaedics, Medical University of Innsbruck, Anichstrasse 35, A6020 Innsbruck, Austria.

- P. Mayrhofer, PhD, Assistant Professor

Institute of Mathematics and Geometry, University of Innsbruck, Technikerstrasse 113, A-6020 Innsbruck Austria.

Correspondence should be sent to Dr P. E. Beaulé at the Department of Orthopaedics, David Geffen School of Medicine, UCLA, 1245 16th Street, Suite 202, Santa Monica, California 90404; email: pbeaule@laoh.ucla.edu

(C)2005 British Editorial Society of Bone and

Joint Surgery

doi:10.1302/0301-620X.87B5. $15377 \$ 2.00$

$J$ Bone Joint Surg $[\mathrm{Br}]$ 2005;87-B:741-4.

Received 6 February 2004;

Accepted after revision

25 August 2004

\title{
EBRA-FCA for measurement of migration of the femoral component in surface arthroplasty of the hip
}

Studies on the migration of an implant may be the only way of monitoring the early performance of metal-on-metal prostheses. The Ein Bild Roentgen Analyse - femoral component analysis (EBRA-FCA) method was adapted to measure migration of the femoral component in a metal-on-metal surface arthroplasty of the hip using standard anteroposterior radiographs. In order to determine the accuracy and precision of this method a prosthesis was implanted into cadaver bones. Eleven series of radiographs were used to perform a zero-migration study. After adjustment of the femoral component to simulate migration of $3 \mathrm{~mm}$ the radiographs were repeated. All were measured independently by three different observers.

The accuracy of the method was found to be $\pm 1.6 \mathrm{~mm}$ for the $\mathrm{x}$-direction and $\pm 2 \mathrm{~mm}$ for the y-direction (95\% percentile). The method was validated using 28 hips with a minimum follow-up of $\mathbf{3 . 5}$ years after arthroplasty. Seventeen were sound, but 11 had failed because of loosening of the femoral component. The normal (control) group had a different pattern of migration compared with that of the loose group. At $\mathbf{2 9 . 2}$ months, the control group showed a mean migration of $1.62 \mathrm{~mm}$ and $1.05 \mathrm{~mm}$ compared with $4.39 \mathrm{~mm}$ and $4.05 \mathrm{~mm}$ in the failed group, for the centre of the head and the tip of the stem, respectively $(p=0.001)$. In the failed group, the mean time to migration greater than $2 \mathrm{~mm}$ was earlier than the onset of clinical symptoms or radiological evidence of failure, 19.1 versus 32.2 months ( $p=0.001$ ) and 24.8 months $(p=0.012)$, respectively.

EBRA-FCA is a reliable and valid tool for measuring migration of the femoral component after surface arthroplasty and can be used to predict early failure of the implant. It may be of value in determining the long-term performance of surface arthroplasty.

Surface replacement of the hip using a metalon-metal bearing ${ }^{1,2}$ is being re-introduced for the young patient with arthritis of the hip because of the preservation of bone and the ease of revision to a total hip replacement (THR). ${ }^{3}$ Since wear of metal-on-metal bearings is almost imperceptible on radiographs, ${ }^{4}$ migration studies ${ }^{5}$ may be the only way of detecting early failures and of evaluating the long-term survival of the prosthesis. The early measurement of migration of the femoral component in THR has been reported to predict the long-term clinical outcome. ${ }^{6-10}$ Several methods

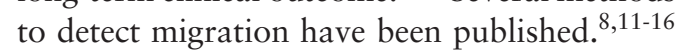
Radiostereometric analysis (RSA) is the most dependable, with an accuracy of $0.2 \mathrm{~mm},{ }^{11,12}$ but it requires prospective planning, the implantation of tantalum markers and stereoradiographs. Ein Bild Roentgen Analyse-femoral component analysis (EBRA-FCA) is a method for measuring migration of the femoral component which can be used retrospectively.
It has a specificity of $100 \%$ and a sensitivity of $78 \%$ for detecting migration of $1 \mathrm{~mm} .{ }^{13}$

We have used EBRA-FCA to measure migration of the prosthesis in resurfacing arthroplasty and to determine its accuracy and precision both in vitro and clinically.

Material and Methods

EBRA-FCA software for surface arthroplasty of the hip. The original EBRA-FCA software was modified for use in surface replacement arthroplasty. The centre of the femoral head is the first reference point and using two more points the central axis of the stem is calculated. The intersection of this axis with the distal tip of the stem determines the second reference point. The central axis of the femur is defined by one point marking the medial cortex and another the lateral cortex. Both trochanters are marked by two orthogonal tangents (Fig. 1a).

Defined reference lines in the $\mathrm{x}$ - and $\mathrm{y}$-axes of a series of radiographs of each patient are 


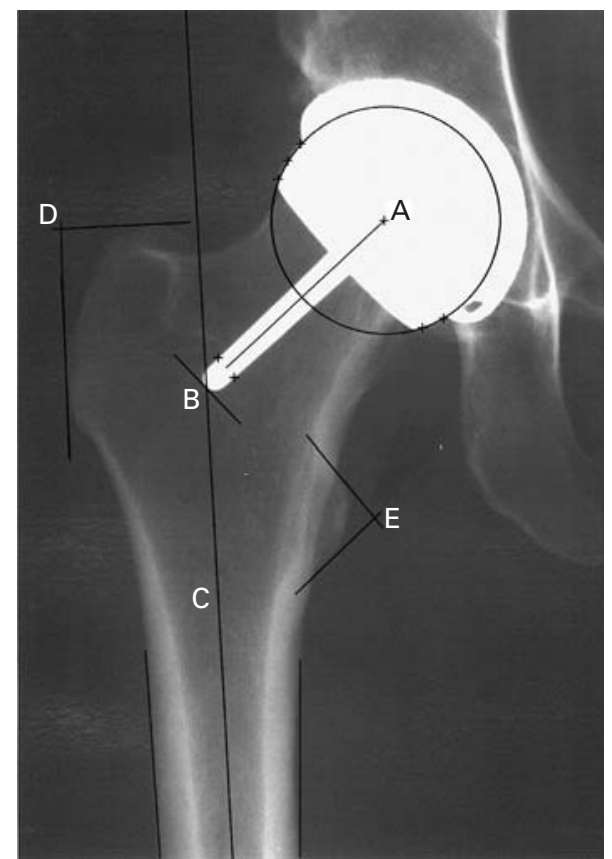

Fig. 1a

\section{EBRA / FCA - GRAPHICS 2001}

Patient name \& ID \#

observation period: 32 months

number of radiographs: 4

comparability limit: $2 \mathrm{~mm}$

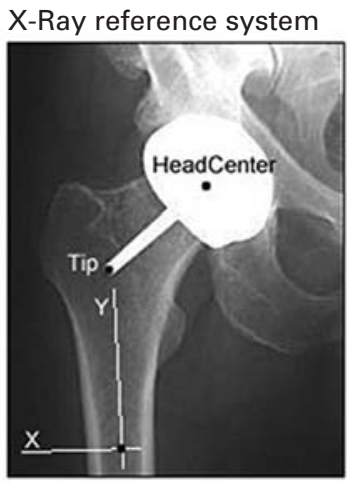

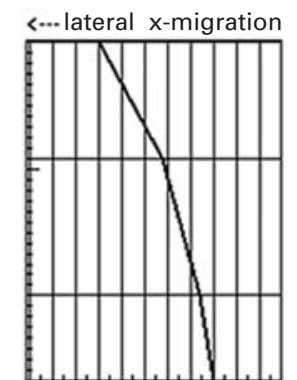

HeadCenter

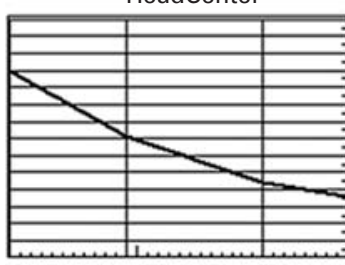

$\square y$-migration
... lateral x-migration

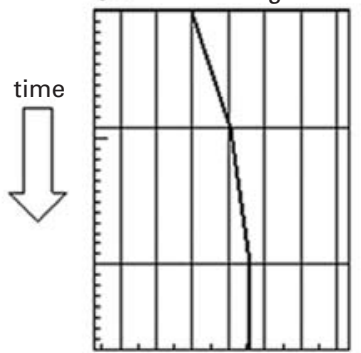

Tip of stem

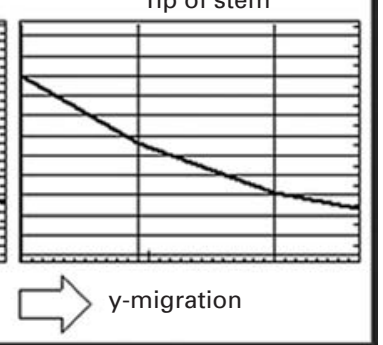

Fig. 1b

Figure 1a-Graphic computer program of EBRA-FCA for surface arthroplasty of the hip. Setting of reference lines: A, centre point of the prosthetic head $B$, tip of the stem; C, femoral axis; D, reference point of the greater trochanter (intersection of the two tangents) and $E$, reference point of the lesser trochanter (intersection). Figure 1b-EBRA-FCA generated migration curves of a 39-year-old-man who had a revision at 39 months for aseptic loosening of the femoral component.

compared (Fig. 1b). Migration is only measured between pairs of radiographs with comparable reference lines for the prosthesis with less than $3 \mathrm{~mm}$ difference; the others are excluded. ${ }^{13}$

To test for the reliability and accuracy of the new EBRAFCA software, a zero migration study and a simulated migration study were undertaken. All measurements were carried out by three observers independently (SW, MM, RB). A Conserve Plus surface arthroplasty (Wright Medical Technology, Arlington, Tennessee) was implanted into the femur and the hemipelvis of a cadaver. The cup was cemented to achieve secure fixation despite being originally designed for cementless fixation. The femoral component was detached from the femoral neck before polymerisation of the cement, so that it could be removed and re-attached, preserving the cement bed of the shaft of the prosthesis. A model was constructed which allowed flexion/extension and simultaneous rotation of the hip in steps of $1^{\circ}$ (Fig. 2). Studies were carried out in $-5^{\circ}$ to $+25^{\circ}$ of flexion and $-10^{\circ}$ to $+50^{\circ}$ of external rotation (mean values $\pm 2 \mathrm{SD}$ ). ${ }^{17}$ We took 11 series of radiographs, with seven radiographs per series. The positions were randomised within the limits set by Ilchmann and Winter, ${ }^{17}$ and predetermined by SAS statistical software (SAS Institute, Cary, North Carolina). Within each set of measurements the migration should be zero and any deviation from this measurement represents observer error. A simulated migration of $3 \mathrm{~mm}$ along the longitudinal axis of the femoral neck was carried out by

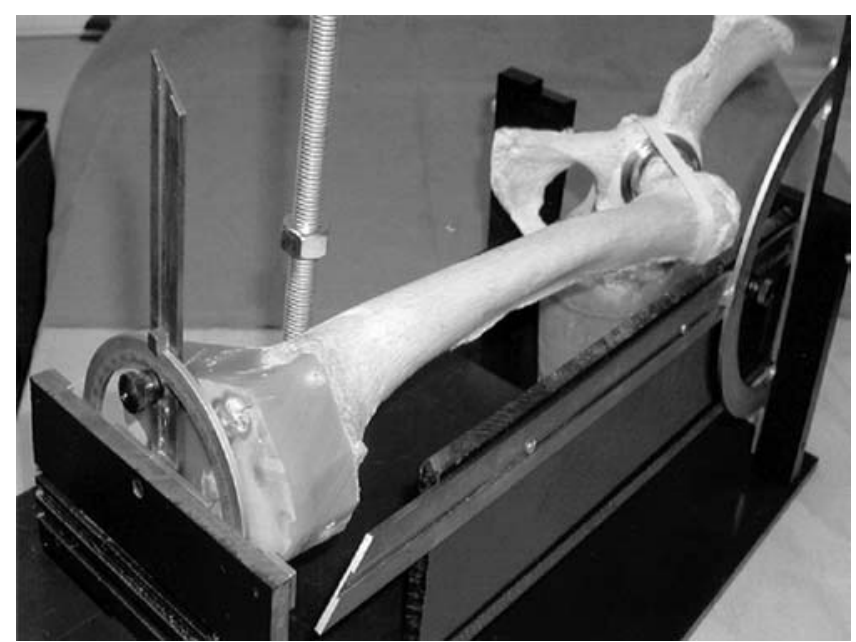

Fig. 2

Photograph of the cadaver model for the experimental analysis of accuracy.

removing three slim rings stepwise, each $1 \mathrm{~mm}$ thick, thus allowing the prosthesis to sink. Allowing for the anteversion of the femur of $15^{\circ}$, the projected migration of the prosthesis along both the $\mathrm{x}$ - and the $\mathrm{y}$-axes on the radiograph was $2.1 \mathrm{~mm}$. Any deviation from this was regarded as an error of measurement.

Prediction of failure. Clinical validation was tested on 28 hips from a series of 400 surface arthroplasties. Group 1 
Table I. Detailed statistical data of the results of the zero-migration study and the simulation of $3 \mathrm{~mm}$ of migration

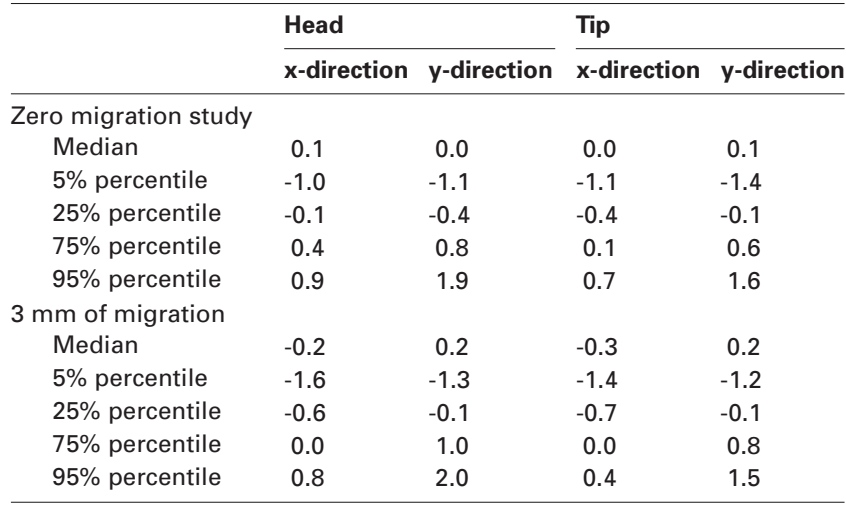

Table II. Sensitivity and specificity of EBRA-FCA for surface arthroplasty

\begin{tabular}{lll}
\hline & Sensitivity & Specificity \\
\hline Head $x$-axis & 0.78 & 0.83 \\
Tip $x$-axis & 0.87 & 0.83 \\
Head $y$-axis & 0.51 & 0.86 \\
Tip y-axis & 0.43 & 0.85 \\
\hline
\end{tabular}

consisted of 17 hips free from any clinical or radiological signs of loosening with a minimum follow-up of five years (mean 6.7 years). Group 2 included 11 revisions for femoral loosening with a mean follow-up of 6.7 years (5.9 to 7.2).

In group 1, there were 12 men and five women with a mean age of 53 years (36 to 67$) ; 12(71 \%$ ) had osteoarthritis, three $(17 \%)$ osteonecrosis and post-traumatic osteonecrosis, developmental dysplasia one $(6 \%)$ and one $(6 \%)$ juvenile rheumatoid arthritis. In group 2 , there were seven men and four women with a mean age of 47.4 years ( 28 to $55)$; seven $(64 \%)$ had osteoarthritis, two $(18 \%)$ osteonecrosis, and one $(9 \%)$ post-traumatic osteoarthritis and one $(9 \%)$ developmental dysplasia. We recorded the overall migration and the time to its initiation. Overall migration was defined as the magnitude, expressed in millimetres, of the vector sum of migrations along both the $\mathrm{x}$ - and $\mathrm{y}$-axes for a given point of interest, i.e. the centre of the head or the tip of the stem. The time when radiological migration became greater than $1 \mathrm{~mm}^{18}$ and of the onset of hip pain were also recorded.

Statistical analysis. Statistical analysis was performed using the SPSS 11.0 statistical software package (SPSS Inc, Chicago, Illinois). Quantitative variables were described by the median, the interquartile range and $5 \%$ and $95 \%$ percentiles. The sensitivity and specificity of the program for detecting migration of more than $2 \mathrm{~mm}$ was calculated by means of a cross-classified table. Sensitivity $(\mathrm{t})$ was calculated as follows: $t=R P /(R P+F N)$. Specificity ( $(s p)$ was calculated by the formula: $s p=\mathrm{RN} /(\mathrm{RN}+\mathrm{FP})(\mathrm{RP}=$ correctpositive results, $\mathrm{FN}=$ false negative results, $\mathrm{RN}=$ correct - negative results, $\mathrm{FP}=$ false positive results). The Spearman correlation coefficient was used to test interobserver error. Student's $t$-test was used to detect differences between the two clinical groups.

\section{Results}

We excluded $20 \%$ of the radiographs because they were not comparable with the other films of a series.

Precision. The overall mean precision of the measurements of the three independent observers was 0.655 (Spearman correlation coefficient) representing an intermediate precision of the program. The mean correlation coefficient of the measurements on the $\mathrm{x}$-axis was 0.51 (intermediate) for the head and 0.68 (intermediate) for the tip of the prosthesis and in the y-direction 0.65 (intermediate) for the head and 0.78 (high) for the tip of the prosthesis.

Accuracy. The overall accuracy of the method was \pm 1.6 $\mathrm{mm}$ for the $\mathrm{x}$-direction and $\pm 2 \mathrm{~mm}$ for the $\mathrm{y}$-direction (95\% percentile). The statistical results of all measurements are presented in detail in Table I.

To determine the sensitivity and specificity of the program for detecting a migration of $2 \mathrm{~mm}$, four cross-classified tables containing the migration data of the head and tip were generated for the $\mathrm{x}$ - and $\mathrm{y}$-directions. The sensitivity and specificity for both axes are summarised in Table II.

Prediction for failure. The two groups did not differ significantly in terms of age, diagnosis and gender $(\mathrm{p}>0.05)$. The hips which failed (group 2) showed significantly greater migration than the normal hips (group 1) with $4.39 \mathrm{~mm}$ versus $1.62 \mathrm{~mm}$ for the centre of the head $(\mathrm{p}=0.001)$ and $4.05 \mathrm{~mm}$ versus $1.05 \mathrm{~mm}$ for the tip of the stem $(\mathrm{p}=0.001)$. In group 2, migration began at a mean of 19.1 months (11 to 51), whereas in group 1 the pattern of migration was consistent with stability of the implant at a mean time of 29.2 months (22 to 39). In the hips which failed (group 2), the mean time to the first migration detected by EBRA-FCA was significantly less than that to the first reported onset of pain: 19.1 months versus 32.2 months $(p=0.001)$. More importantly, the time to detection of significant migration was shorter than that to detection of radiolucency of the metaphyseal stem, 19.1 months versus 24.3 months ( $\mathrm{p}=$ 0.012 ).

\section{Discussion}

The application of EBRA-FCA to study migration of the femoral component in surface arthroplasty has shown it to be a reliable tool with a low probability of false-positive migration, but an underestimation of migration in the $y$ direction. This effect is already known from the original EBRA-FCA program and is explained by the comparability algorithm of the software, which leads to an improvement in accuracy, but also to an underestimation of subsidence by smoothing of the migration curve. Nonetheless, in our clinical series, all of the hips which were revised for femoral loosening showed a significantly earlier and greater migration than the normal hips, with an onset of migration which 
occurred before the appearance of radiological signs of loosening. Migration of $2 \mathrm{~mm}$ or more in the first two years was predictive of failure of the implant within five years, which confirmed the validity of this version of EBRA-FCA.

Our findings are in accordance with those made for conventional THR ${ }^{6,7,19}$ which showed the correlation of vertical migration of the femoral stem with clinical failure. Movement of 1 to $2 \mathrm{~mm}$ represented significant migration. ${ }^{12,20,21}$ Although EBRA-FCA is not as accurate as RSA, it does not require the implantation of tantalum markers ${ }^{22}$ and can be done retrospectively for large numbers of patients. The method allows the identification of clinical and surgical factors related to early migration as well as a comparison of different designs of implant. ${ }^{23}$

The authors would like to acknowledge the William G. McGowan Charitable Fund, Inc for grant support.

One or more of the authors have received or will receive benefits for personal or professional use from a commercial party related directly or indirectly to the subject of this article. In addition, benefits have been or will be directed to a research fund, foundation, educational institution, or other nonprofit organisation with which one or more of the authors are associated.

\section{References}

1. Daniel J, Pynsent PB, McMinn DJW. Metal-on-metal resurfacing of the hip in patients under the age of 55 years with osteoarthritis. J Bone Joint Surg [Br] 2004; 86-B:177-85

2. Amstutz HC, Beaulé PE, Dorey FJ, et al. Metal-on-metal hybrid surface arthroplasty: two to six year follow-up study. J Bone Joint Surg [Am] 2004;86-A:28-39.

3. Beaulé PE, Amstutz HC. Surface arthroplasty of the hip revisited: current indications and surgical technique. In: Sinha RJ, ed. Hip replacement: current trends and controversies. New York: Marcel Dekker Inc., 2002:261-97.

4. Sieber H-P, Rieker CB, Kottig P. Analysis of 118 second-generation metal-onmetal retrieved hip implants. J Bone Joint Surg [Br] 1999;81-B:46-50.

5. Mjoberg B. Theories of wear and loosening in hip prostheses: wear-induced loosening vs loosening-induced wear-a review. Acta Orthop Scand 1994;65:361-71.

6. Krismer M, Biedermann R, Stockl B, et al. The prediction of failure of the stem in THR by measurement of early migration using EBRA-FCA. J Bone Joint Surg [Br]1999; $81-\mathrm{B}: 273-80$
7. Freeman MAR, Plante-Bordeneuve P. Early migration and late aseptic failure of proximal femoral prostheses. J Bone Joint Surg [Br] 1994;76-B:432-8.

8. Walker PS, Mai SF, Cobb AG, Bentley G, Hua J. Prediction of clinical outcome of THR from migration measurements on standard radiographs: a study of cemented Charnley and Stanmore femoral stems. J Bone Joint Surg [Br] 1995;77-B:705-14.

9. IIchmann T, Markovic L, Joshi A, et al. Migration and wear of long-term successful Charnley total hip replacements. J Bone Joint Surg [Br] 1998;80-B:377-81.

10. Kobayashi A, Donnelly WJ, Scott G, Freeman MAR. Early radiological observations may predict the long-term survival of femoral hip prostheses. J Bone Joint Surg [Br] 1997;79-B:583-9.

11. Selvik G. Roentgen stereophotogrammetry: a method for the study of the kinematics of the skeletal system. Acta Orthop Scand Supp/ 1989;232:1-51.

12. Karrholm J, Herberts $\mathbf{P}$, Hultmark $\mathbf{P}$, et al. Radiostereometry of hip prostheses: review of methodology and clinical results. Clin Orthop 1997;344:94-110.

13. Biedermann R, Krismer M, StockI B, et al. Accuracy of EBRA-FCA in the measurement of migration of femoral components of total hip replacement. J Bone Joint Surg [Br] 1999;81-B:266-72.

14. Krismer M, Bauer R, Tschupik J, Mayrhofer P. EBRA: a method to measure migration of acetabular components. J Biomech 1995;28:1225-36.

15. Hardinge $K$, Porter $M$, Jones $P$, Hukins $D$, Taylor $G$. Measurement of hip prostheses using image analysis: the MAXIMA hip technique. J Bone Joint Surg [Br] 1991; 73-B:724-8.

16. Sutherland CJ, Wilde AH, Borden LS, Marks KE. A ten-year follow-up of one hundred consecutive Muller curved-stem total hip-replacement arthroplasties. $J$ Bone Joint Surg [Am] 1982;64-A:970-82

17. Ilchmann T, Winter E. Migration, subsidence and wear after hip replacement. Hip 1999;9:104-11.

18. Beaule PE, Dorey FJ, LeDuff MJ, Gruen T, Amstutz HC. Risk factors affecting outcome of metal-on-metal surface arthroplasty of the hip. Clin Orthop 2004;418: 87-93

19. Karrholm J, Borssen B, Lowenhielm G, Snorrason F. Does early micromotion of femoral prostheses matter? 4-7 year stereoradiographic follow-up of 84 cemented hip prostheses. J Bone Joint Surg [Br] 1994;76-B:912-17.

20. Nistor L, Blaha JD, Kjellstrom U, Selvik G. In vivo measurements of relative motion between uncemented femoral total hip component and the femur by roentgen stereophotogrammetric analysis. Clin Orthop 1991;269:220-7.

21. Karrholm J, Snorrason F. Subsidence, tip, and bump micromovements of noncoated ribbed femoral prostheses. Clin Orthop 1993;287:50-60.

22. Eldridge JD, Avramidis K, Lee M, Learmonth ID. Tantalum ball position after total hip arthroplasty. J Bone Joint Surg [Br] 1998;80-B:414-16.

23. Hamadouche $\mathbf{M}$, Witvoet $\mathbf{J}$, Porcher $\mathbf{R}$, et al. Hydroxyapatite-coated versus gritblasted femoral stems: a prospective, randomised study using EBRA-FCA. J Bone Joint Surg [Br] 2001;83-B:979-87. 